Article is available online at http://www.webio.hu/por/2004/10/4/0197

ARTICLE

\title{
Increased Predisposition to Cancer in Brothers and Offspring of Testicular Tumor Patients
}

\author{
Sarolta GUNDY, ${ }^{1}$ Mária BABOSA, ${ }^{3}$ Márta BAKI, ${ }^{2}$ István BODROGI ${ }^{2}$ \\ ${ }^{1}$ Department of Onco-Cytogenetics and ${ }^{2}$ Department of Chemotherapy, National Institute of Oncology, Budapest, \\ ${ }^{3}$ Second Clinic of Paediatrics, Semmelweis University, Budapest, Hungary
}

\begin{abstract}
Cancer susceptibility was examined in first-degree relatives of 293 testicular tumor patients (TTPs) and 586 age-matched healthy males. Significantly increased risk was found in the families of TTPs (OR: 1.4; CI: 1.08-1.79), however, except for testicular cancer of 7 brothers (OR: 11.7; CI: 1.42-256.5), and 6 various childhood tumors (bilateral Wilms' tumor, neuroblastoma, medulloblastoma, ALL, histiocytosis-X, testicular tumor) of 200 offspring (OR: 12.9; CI: 1.54-286.2), no association with other malignancies was observed. No differences were seen between the fertility of patients and controls when occupational or socio-economic status of the families was taken into account. However, the majority of the controls (85\%) fathered the first child between $20-30$ years of
\end{abstract}

age, while only $61 \%$ of TTPs had the first child in the same age group. TTPs fathered more girls than boys $(P=0.009)$, and the lower male - higher female ratio of index children was also identical, irrespective of the conception taking place before or after the father's treatment. Occupations did not, but smoking might have influenced cancer susceptibility of the patients. Aggregation of fraternal testicular tumors, and both dramatically increased cancer risk and altered sex ratio of the offspring indicate a remarkable role of hereditary factors in tumorigenesis and later consequences of a certain portion of testicular malignancies, which must be refined by molecular studies. (Pathology Oncology Research Vol 10, No 4, 197-203)

Keywords: testicular cancer; familial cancer risk; childhood tumors

\section{Introduction}

Several studies have shown that the risk of developing testicular cancer has increased rapidly over the past 40 years, ${ }^{1,2}$ but it is still unclear how the gene-environment interactions may play a role in accelerating the development of this malignancy. Moreover, these circumstances raise the question whether the likelihood to accumulate a cascade of mutations in genetically unstable germ cells might affect cancer susceptibility of the offspring of these patients. Familial clustering of testicular cancer ${ }^{3-7}$ and the occurrence of bilateral tumors ${ }^{8-11}$ seem to be good argu-

Received: Oct 13, 2004; accepted: Nov 20, 2004

Correspondence to: Sarolta GUNDY, MD, PhD; National Institute of Oncology, Budapest, Ráth Gy. u. 7-9., H-1122 Hungary. Tel: 36/1/224-8779, Fax: 36/1/224-8776, E-mail: gundy@oncol.hu

This work was supported by Grants 16003 OTKA and JF 391, awarded by the National Scientific Research Fund of Hungary and the US-Hungarian Science and Technology Joint Fund. ments in favor of an influence of genetic factors. Common environment of family members, ${ }^{12}$ endogenous and exogenous sources of exposure, ${ }^{8-13}$ and increased worldwide incidence of the disease ${ }^{1,14}$ suggest the importance of environmental factors. Socio-economic status, which is determined mainly by occupations in this part of Europe, may further modify the life styles, dietary habits, and reproductive practices of testicular tumor patients (TTPs) and their family members. ${ }^{8,15}$ Under these circumstances TTPs and their families are particularly concerned whether the offspring conceived from these fathers have an excess risk to develop cancer. The present case-control study raises additional issues regarding genetic and/or environmental components in the etiology, and later consequences of testicular tumors. Cancers reported in firstdegree relatives and the role of occupational exposures and smoking habits were examined in TTPs and agematched healthy males. Since testicular cancer develops due to multiple genetic alterations of the germ cells, we also discuss whether fertility of TTPs might be changed 
due to the impact of the disease itself or the treatment, and men with germ cell tumors may have a baseline genomic instability that would increase risk for cancer susceptibility of the offspring.

\section{Patients and Methods}

Patients that entered this study were diagnosed with histologically confirmed stage I or II testicular cancer, and seen after post-orchiectomy at the National Institute of Oncology, Budapest, between 1989 and 1997. Details of the disease were recorded in the hospital. A total of 331 eligible patients were identified for initial recruitment, and gave consent to participate in the study. At the personal interviews patients were asked to report about natural parents, the number of blood-related siblings and biological offspring, and whether any first-degree relative has been diagnosed as having cancer. The age of the offspring, and whether the children were conceived before or after the termination of the father's treatment were also recorded. Out of 331 patients 293 (88.5\%) were convinced to give accurate reports regarding the site of cancer in first-degree relatives, while 38 patients $(11.5 \%)$ were excluded from the study, mostly due to inaccurate reports regarding the relatives' cancer sites, and/or other reasons (refused to participate, mental deficiency, second cancers, etc). As regards environmental exposures, three-year duration of employment and one-year duration of smoking habits prior to the interview were also asked.

For every case 2 age-matched cancer-free, healthy controls were chosen out of 1570 volunteers from a database prepared for other reasons. They were interviewed under the same circumstances as TTPs, and were chosen so that their ages could be matched with less than 2 years difference to those diagnosed with testicular cancer. Thus, 586 healthy males were age-matched, selected as attending pre-employment medical examinations, routine laboratory tests, or being blood donors and thus considered healthy. Cancer cases in the controls' families were also selfreported. Cases and controls were categorized into 4 broad occupational groups with at least three-year duration of the current employment before the interview. Teachers, clerks, state employees, students, and different administrative staff members without known occupational exposures were recorded as intellectuals. Rural farmers exposed mainly to plant-protecting agents were classified as agricultural population. The group comprising industrial and certain manual workers (joiners, locksmiths, painters, turners, miners), as well as drivers and gasoline station workers were considered as representatives exposed to chemical mutagens in industrial production and transportation. Those whose job was not related to known exposures e.g. mechanics, electricians, military men, waiters, salesmen, construction workers, and 2 condemned and
Table 1. Data on testicular tumor patients and age-matched healthy controls

\begin{tabular}{|c|c|c|}
\hline Data on persons & $\begin{array}{l}\text { Testicular tumor } \\
\text { patients }\end{array}$ & Controls \\
\hline Total number of persons & 293 & 586 \\
\hline Age (years; mean \pm SD) & $35.2 \pm 9.7$ & $34.8 \pm 7.9$ \\
\hline Range & $18-58$ & $18-58$ \\
\hline \multicolumn{3}{|l|}{ Histology } \\
\hline Seminomas & $89(30.4 \%)$ & \\
\hline Non-seminomas & $199(67.9 \%)$ & \\
\hline Extragonadal & $5(1.7 \%)$ & \\
\hline Bilaterality & $6(2.0 \%)$ & \\
\hline Age at onset of seminomas & $41.5 \pm 7.6$ & \\
\hline Age at onset of non-seminomas & as $33.8 \pm 8.6$ & \\
\hline \multicolumn{3}{|l|}{ Number of } \\
\hline Fathers & 293 & 586 \\
\hline Mothers & 293 & 586 \\
\hline Brothers & 107 & 168 \\
\hline Sisters & 262 & 551 \\
\hline Offspring & 200 & 418 \\
\hline Families with children & $146(49.8 \%)$ & $307(52.4 \%)$ \\
\hline Number of child/family & 0.68 & 0.71 \\
\hline Total of first-degree relatives & 1155 & 2309 \\
\hline \multicolumn{3}{|l|}{ Occupations } \\
\hline Intellectual & $92(31.4 \%)$ & $198(33.8 \%)$ \\
\hline Agriculture & $23(7.8 \%)$ & $53(9.1 \%)$ \\
\hline Industry & $103(35.2 \%)$ & $227(38.7 \%)$ \\
\hline Others & $75(25.6 \%)$ & $108(18.4 \%)$ \\
\hline \multicolumn{3}{|l|}{ Smoking habits } \\
\hline Smokers & $158(53.9 \%)$ & $202(34.5 \%)$ \\
\hline Nonsmokers & $135(46.1 \%)$ & $384(65.5 \%)$ \\
\hline
\end{tabular}

1 jobless but previously nonexposed, were classified as others. The smoking habit was registered as being smoker or non-smoker for at least 1 year before the interview. All analyses were performed using GraphPad Instat (Version 3.05, 2000 GraphPad Software, Inc.) computer program. The measure of statistical association used was the odds ratio with $95 \%$ confidence intervals (CIs), and $\mathrm{P}$ value of 0.05 was considered as the limit of significance.

\section{Results}

Details on the data of TTPs and age-matched controls are given in Table 1. Histology and staging of the disease were recorded in the hospital. Age of the patients with non-seminoma type cancers was significantly lower than that of ones with seminoma $(\mathrm{P}=0.01)$, and twice more patients had nonseminomas than seminomas in this cohort. As regards occupational histories, the summarized number of exposed TTPs (industry, transport, and agriculture) did not differ from 
those in the controls ( $43 \%$ vs. $48 \%$ ). While only $34.5 \%$ of the controls were tobacco smokers, more than half of TTPs (53.9\%) smoked for at least one year before the diagnosis. As a possible indicator of parental fertility, the number of descendants and male/female ratio showed no differences between families of cases and controls $(\mathrm{P}=0.26$ and $\mathrm{P}=0.21$, respectively). We recorded 119 cancer cases in 1155 firstdegree relatives of TTPs $(10.3 \%)$, which was significantly higher than 176 cancer occurrences (7.6\%) found in 2309 first-degree relatives of the controls (Table 2). Our observations suggest that first-degree relatives of TTPs have 1.4 times higher risk ( $\mathrm{P}=0.007$; $\mathrm{CI}$ : $1.08-1.79)$ to develop cancer than those of cancer-free controls. Significant increase in frequency of malignancies was recorded in brothers $(\mathrm{P}=0.001 ;$ OR: 4.91; CI: 1.58-16.17) and offspring $(\mathrm{P}=0.005$; OR: 12.90 ; CI: 1.54-286.2) of TTPs, but not in fathers, mothers or sisters.

When specific cancers were analyzed between the relatives of the two groups, no excess of any cancers was found except testicular cancer occurring in 7 brothers, in one of the sons, and in one of the fathers of index patients (Table 3). Altogether 9 testicular tumors were recorded in 484 male relatives of index patients (1.9\%) compared with 1 out of 974 control relatives $(0.1 \%)$. The brothers seem to be at 11.7-fold risk $(\mathrm{P}=0.004$; CI: 1.42-256.5) of developing testicular malignancy. Out of the 293 patients bilateral testicular cancers were seen in 6 cases $(2.05 \%)$, and additionally, 2 brothers (one of them is a monozygotic twin of a proband with unilateral tumor) also had bilateral form of the disease. This finding reflected $2.6 \%$ occurrence of bilaterality when all TTPs (302 persons) were taken into account. Bilateral cancer was diagnosed in one case simultaneously, while in the remaining cases it occurred 6-7 years following the first cancer.

No cancer was found among family members in $76.8 \%$ of the controls, and in $63.8 \%$ of the TTPs, respectively (OR: 0.533; CI: 0.393-0.724), while one cancer occurred among the relatives in $18.9 \%$ of the controls, and in a nearly doubled proportion (33.4\%) of TTPs (OR: 2.151; CI: 1.564-2.958). Two or more affected family members were

Table 2. Localization of cancers in first-degree relatives of testicular tumor patients and age-matched cancer-free controls

\begin{tabular}{|c|c|c|c|c|c|c|c|c|c|c|c|c|}
\hline \multirow{2}{*}{ Localization } & \multicolumn{2}{|c|}{ Fathers } & \multicolumn{2}{|c|}{ Mothers } & \multicolumn{2}{|c|}{ Brothers } & \multicolumn{2}{|c|}{ Sisters } & \multicolumn{2}{|c|}{ Offspring } & \multicolumn{2}{|c|}{ Total cancers } \\
\hline & TTP & Control & TTP & Control & TTP & Control & TTP & Control & TTP & Control & TTP & Control \\
\hline Lung & 10 & 23 & 2 & 9 & - & - & - & 1 & - & - & 12 & 33 \\
\hline Colorectal & 9 & 15 & 2 & 9 & - & - & 2 & 3 & - & - & 13 & 27 \\
\hline Stomach & 11 & 14 & 6 & 8 & 1 & 2 & - & - & - & - & 18 & 24 \\
\hline Breast & - & - & 4 & 12 & - & - & 2 & 3 & - & - & 6 & 15 \\
\hline Ovary & - & - & 6 & 7 & - & - & 1 & 1 & - & - & 7 & 8 \\
\hline Testis & 1 & 1 & - & - & 7 & - & - & - & $1(\mathrm{M})$ & - & 9 & 1 \\
\hline Prostate & 2 & 4 & - & - & 2 & - & - & - & - & - & 4 & 4 \\
\hline Head and neck & 9 & 17 & - & - & 1 & - & - & - & - & - & 10 & 17 \\
\hline Uterus & - & - & 8 & 6 & - & - & - & - & - & - & 8 & 6 \\
\hline Liver & 4 & 4 & - & - & - & 1 & - & - & - & - & 4 & 5 \\
\hline Gall- bladder & - & - & 4 & 5 & - & - & - & - & - & - & 4 & 5 \\
\hline Esophagus & - & 3 & - & - & - & 1 & - & - & - & - & - & 4 \\
\hline Pancreas & 3 & 4 & 2 & 5 & - & - & - & - & - & - & 5 & 9 \\
\hline Bladder & 2 & 3 & - & - & 1 & - & - & - & - & - & 3 & 3 \\
\hline Kidney & - & 2 & - & - & - & - & - & 1 & - & - & - & 3 \\
\hline Brain & - & - & 2 & 1 & - & - & - & 1 & $1(\mathrm{M})$ & - & 3 & 2 \\
\hline Leukemia & - & - & - & 1 & 1 & 1 & - & 2 & $1(\mathrm{M})$ & - & 2 & 4 \\
\hline Lymphoma & - & - & - & - & - & - & 1 & 1 & - & - & 1 & 1 \\
\hline Cervix & - & - & 2 & 2 & - & - & - & - & - & - & 2 & 2 \\
\hline Thyroid & - & - & 2 & 1 & - & - & - & 1 & - & - & 2 & 2 \\
\hline Melanoma & - & - & - & - & 1 & - & 1 & 1 & - & - & 2 & 1 \\
\hline Neuroblastoma & - & - & - & - & - & - & - & - & $1(\mathrm{~F})$ & - & 1 & - \\
\hline Wilms' tumor & - & - & - & - & - & - & - & - & $1(\mathrm{~F})$ & - & 1 & - \\
\hline Histiocytosis- $X$ & - & - & - & - & - & - & - & - & $1(\mathrm{~F})$ & - & 1 & - \\
\hline Sarcoma & - & - & 1 & - & - & - & - & - & - & & 1 & - \\
\hline All sites (n) & 51 & 90 & 41 & 66 & 14 & 5 & 7 & 15 & 6 & 0 & 119 & 176 \\
\hline Persons examined & 293 & 586 & 293 & 586 & 107 & 168 & 262 & 551 & 200 & 418 & 1155 & 2309 \\
\hline$\%$ of cancer cases & 17.4 & 15.4 & 14.0 & 13.1 & $11.2^{*}$ & 3.0 & 2.7 & 2.7 & $3.0^{*}$ & 0 & $10.3^{*}$ & 7.6 \\
\hline
\end{tabular}

*Significantly differs from the control: $\mathrm{P}<0.05$; M: male, F: female 
Table 3. Occurrence of testicular tumors in first-degree relatives of 293 testicular cancer patients

\begin{tabular}{|c|c|c|c|c|}
\hline Family & Relationship & Age at diagnosis & Side & Histology of the tumor \\
\hline \multirow[t]{2}{*}{1.} & Proband & 39 & $\mathrm{R}$ & Embryonal carcinoma + seminoma \\
\hline & Brother & 31 & $\mathrm{~L}$ & Seminoma \\
\hline \multirow[t]{2}{*}{2.} & Proband & 30 & $\mathrm{R}$ & Seminoma \\
\hline & MZ twin brother & 24,30 & $\mathrm{R}+\mathrm{L}$ & Embryonal carcinoma + seminoma \\
\hline \multirow[t]{2}{*}{3.} & Proband & 22,29 & $\mathrm{R}+\mathrm{L}$ & Teratoma + embryonal carcinoma \\
\hline & Brother & 31 & $\mathrm{~L}$ & Teratoma + embryonal carcinoma \\
\hline \multirow[t]{2}{*}{4.} & Proband & 23,29 & $\mathrm{R}+\mathrm{L}$ & Adult teratoma + embryonal carcinoma + seminoma \\
\hline & Brother & 27,43 & $\mathrm{R}+\mathrm{L}$ & Seminoma \\
\hline \multirow[t]{2}{*}{5.} & Proband & 33 & $\mathrm{~L}$ & Embryonal carcinoma + seminoma \\
\hline & Brother & 18 & $\mathrm{~L}$ & Adult teratoma + embryonal carcinoma \\
\hline \multirow[t]{2}{*}{6.} & Proband & 23 & $\mathrm{R}$ & Teratoma + embryonal carcinoma \\
\hline & Brother & 37 & $\mathrm{~L}$ & Seminoma \\
\hline \multirow[t]{2}{*}{7.} & Proband & 34 & $\mathrm{~L}$ & Seminoma \\
\hline & MZ twin brother & 30 & $\mathrm{~L}$ & Adult teratoma + embryonal carcinoma \\
\hline \multirow[t]{2}{*}{8.} & Proband & 36 & $\mathrm{~L}$ & Seminoma \\
\hline & Son & 17 & $\mathrm{~L}$ & Adult teratoma + embryonal carcinoma \\
\hline \multirow[t]{2}{*}{9.} & Proband & 41 & $\mathrm{R}+\mathrm{L}$ & Embryonal carcinoma + seminoma \\
\hline & Father & 47 & $\mathrm{~L}$ & Seminoma \\
\hline
\end{tabular}

R: right, L: left, MZ: monozygotic

seen with equal frequency in families of both groups, indicating that the risk of having 2 or more cancers is similar among relatives of diseased and healthy males (Table 4). Our observations showed no association of testicular tumor with any known dominantly inherited cancer syndromes. When the cancer occurrences in the offspring were analyzed (Table 2, Table 5) no childhood tumors were found in control families, but 6 cases were recorded among the offspring of TTPs $(\mathrm{P}=0.005$; OR: 12.9; CI: 1.54-286.2), emphasizing their strong predisposition, and a 12.9-fold risk to develop cancer. Three boys and 3 girls had malignancies under the age of 17 years. Only one child (a girl with neuroblastoma) was conceived after the termination of the father's treatment ( 9 months), while 5 children, with bilateral Wilms' tumor, medulloblastoma, acute lymphoid leukemia, histiocytosis-X, and testicular tumor, were conceived $8.5,2.5,14,4$, and 17 years, respectively, before the onset of the fathers' disease. Out of 293 TTPs 146 fathered children (49.8\%), and of their 200 children $84(42 \%)$ were boys and $116(58 \%)$ girls (Table 5). On the other hand, out of 586 controls 307 fathers $(52.6 \%)$ had 220 boys (53\%) and 198 girls (47\%), which indicates that men with testicular cancer had the same fertility as healthy males, but they fathered more

Table 4. Aggregation of cancer cases in first-degree relatives of testicular cancer patients and age-matched cancer-free controls

\begin{tabular}{lcccc}
\hline & TTPS & Controls & P value & Odds ratio (95\% CI) \\
\hline Total number of persons & $293(100 \%)$ & $586(100 \%)$ & & \\
\hline Number of cancer cases & & & & \\
in first-degree relatives & $187(63.8 \%)$ & $450(76.8 \%)$ & $<0.0001$ & $0.533(0.393-0.724)$ \\
0 & $98(33.4 \%)$ & $111(18.9 \%)$ & $<0.0001$ & $2.151(1.564-2.958)$ \\
1 & $8(2.7 \%)$ & $25(4.3 \%)$ & 0.2588 & $0.630(0.263-1.493)$ \\
$2-4$ & & & & \\
\hline
\end{tabular}


Table 5. Sex ratio and malignancies of the offspring of testicular tumor patients and age-matched controls

\begin{tabular}{|c|c|c|c|c|c|c|c|c|}
\hline \multirow{3}{*}{ Sex of the offspring } & \multicolumn{4}{|c|}{$\begin{array}{l}\text { Offspring conceived according } \\
\text { to the fathers' diagnosis or treatment }\end{array}$} & \multirow{2}{*}{\multicolumn{2}{|c|}{$\begin{array}{l}\text { TTPs' offspring } \\
\text { total }\end{array}$}} & \multirow{2}{*}{\multicolumn{2}{|c|}{$\begin{array}{c}\text { Controls' offspring } \\
\text { total }\end{array}$}} \\
\hline & \multicolumn{2}{|c|}{ before } & \multicolumn{2}{|c|}{ after } & & & & \\
\hline & $n$ & $\%$ & $n$ & $\%$ & $n$ & $\%$ & $n$ & $\%$ \\
\hline Males & 58 & 41.7 & 26 & 42.6 & 84 & 42.0 & 220 & 52.6 \\
\hline Females & 81 & 58.3 & 35 & 57.4 & 116 & 58.0 & 198 & 47.4 \\
\hline Both sexes & 139 & 69.5 & 61 & 30.5 & 200 & 100.0 & 418 & 100.0 \\
\hline $\begin{array}{l}\text { Sex ratio } \\
\text { Males/Females }\end{array}$ & $0.72 / 1$ & $0.74 / 1$ & $0.72 / 1^{*}$ & $1.1 / 1$ & & & & \\
\hline Malignancies & $\begin{array}{c}5 \\
\text { Wilms', brain, } \\
\text { ALL, testis, } \\
\text { histiocytosis-X }\end{array}$ & 3.6 & $\begin{array}{c}1 \\
\text { Neuro- } \\
\text { blastoma }\end{array}$ & 1.6 & 6 & $3.0^{* *}$ & 0 & 0 \\
\hline
\end{tabular}

*Significantly differs from the control: $\mathrm{P}=0.01$

**OR: 12.9; CI: 1.54-286.2

girls than boys $(\mathrm{P}=0.009)$. The lower male - higher female ratio of index children was identical, irrespective of the conception taking place before or after the father's treatment. The age distribution of the fathers at the conception of the first child showed, however, significant differences between the two groups $(\mathrm{P}=0.000)$. The majority of the controls (85\%) fathered the first child between $20-30$ years of age, while only $61 \%$ of TTPs had the first child in the same age group. No differences were seen between patients and controls in fertility and in the number of children when occupational or socio-economic status of the families were taken into account (detailed data are not shown). In order to maximize fertility, cryopreservation was not applied in any of the cases in TTPs. According to histology of the paternal tumors, significantly more children (OR: 6.29; CI: 3.49-9.96) were born from fathers with non-seminomas $(71.5 \%)$ than from those with seminomas $(28.5 \%)$, either they were fathered before or after the termination of the father's treatment.

\section{Discussion}

The most important finding of this study was that malignancies occurred with higher probability in brothers and offspring of TTPs than in those of controls. However, there was no excess in the prevalence of cancers at other sites than testicular tumors of the brothers. It seems that this cancer type does indeed cluster, and probably has genetic background in some TTP families. Similar frequencies (1.3$3.5 \%$ ) were found in other case-control and cohort studies, also indicating a higher fraternal than paternal risk to devel- op testicular cancer. ${ }^{3-6}$ In addition to proband-brother testicular tumor clustering, the presence of bilateral forms is also supposed to have rather biological than treatment-induced origin of malignancy. Nicholson and Harland ${ }^{11}$ assume a $33 \%$ contribution of the hereditary fraction to the occurrence of bilateral testicular cancers, and conclude that genetic factors might be more involved in these cases than expected by chance alone. If we summarize the 9 familial, the 6 bilateral, and the 2 familial and bilateral cases, these results suggest the importance of genetic factors playing a role in a certain subgroup of testicular cancers. The clinical application of this information can be important at genetic counseling of TTPs, to convince their family members, particularly their brothers, to perform self-examinations and participate in different screening programs.

Beside predisposition to fraternal testicular tumors, clustering in some families, there is another important question at genetic counseling: Will children fathered by TTPs have an excess risk to congenital malformations and/or cancer susceptibility? Previously we $\mathrm{e}^{17,18}$ and others ${ }^{19,20}$ found no evidence of elevation in the occurrence of congenital abnormalities in the offspring born either before or after the father's diagnosis or treatment. As regards childhood tumors occurring below 18 years of age, only scanty or indirect data exist, ${ }^{21-23}$ which show generally no increased risk of childhood tumors. We, however, suppose that genetic factors have very likely an impact on the 6 cancer cases occurred in 200 offspring of TTPs. Since the induction of germ cell tumors of fathers is supposed to have started during the embryonic development, ${ }^{24}$ the likelihood to accumulate a cascade of mutations might play a role not only in 
their cancer formation. At certain stages in the development of sperms some DNA regions might be more vulnerable in TTPs than in healthy males, which may increase genomic instability and cancer susceptibility of the offspring. ${ }^{22,25}$ This hypothesis is, however, not supported by findings of Heimdal et al., ${ }^{21}$ who observed no increased risk and only 2 cancer cases out of 1261 offspring of Norwegian and Swedish TTPs during a 10 -year study period. Our findings are remarkable, and pose special tasks to establish a linkage between paternal testicular cancer, and types and induction of these childhood tumors. We found bilateral Wilms' tumor and neuroblastoma occurring in two children of TTPs, which are the most common extracranial tumors in the childhood. The bilateral forms found in these children might occur very likely as the consequence of inherited germ cell mutations. Germline mutations in WT-1 tumorsuppressor gene were identified not only in Wilms' tumor, but also in some urogenital malformations such as undescended testicles, ${ }^{26}$ which was the case of this child's father. Twenty-two percent of neuroblastomas are also estimated to occur due to germinal mutations. ${ }^{27}$ Furthermore, a testicular tumor found in the 17-year-old son of the index patient may also have a dominantly transmitted character as a concordant cancer type. Wilms' tumor, neuroblastoma and testicular tumor were also reported as excess in families with Li-Fraumeni syndrome (LFS) or "incomplete" LFS. $^{28,29}$ Of course, our cases do not meet the classic LFS criteria, since only a theoretical linkage is taken into account between testicular tumor of fathers and childhood tumors of the offspring. However, if we add two further cancers such as acute lymphoid leukemia and brain tumor (medulloblastoma) found in young descendants, they may also appear due to germline p53 mutations ${ }^{29}$ as in LFS. Although it was previously shown that p53 genes are not altered in testicular tumor formation, ${ }^{30}$ a very recent study ${ }^{31}$ reports on a key role of p53 in normal spermatogenesis, which, if damaged, might very likely affect tumorigenesis in a wider spectrum of early onset cancers, perhaps including childhood tumors as well. ${ }^{25,29,31}$

The shift in the male-female ratio in the offspring may also be explained with genetic alterations in the germ cells of the father. The deficiency of Y-chromosomal DNA was recorded in $39 \%$ of testicular tumor cells of Finnish and Norwegian patients. ${ }^{32}$ We do not know how long before the onset of disease the Y chromosome loss occurs, which may also constitute an important step in the tumor development. One can speculate that this phenomenon may alter the genesis and viability of sperm cells containing Y sex chromosomes. Moller ${ }^{33}$ also found a lower proportion of boys in the offspring of Danish TTPs, and suggested that increased paternal age, among others, can probably cause decreased male-female ratio. We cannot exclude this version either, since $38.4 \%$ of TTPs, and only $15 \%$ of controls fathered the first child at ages above 30 .
Interestingly, there was no difference between the fertility of TTPs and age-matched healthy males in our study population. The total number of children was similar in both groups. This observation completely contradicts the findings of others ${ }^{34,35}$ that reported the subfertility of TTPs before, and particularly after the onset of disease. We have no information on family planning and child wish of healthy males and TTPs in this study, however, we may say that the birth rates and fertility indicators in the Hungarian population are much lower than in Nordic countries. ${ }^{36}$

With regard to environmental exposures, socio-economic background of families and occupations for at least 3 years before the onset of disease do not seem to alter either the cancer risk of TTPs or fertility rates in cases and controls (not shown). This observation is in accordance with many others. ${ }^{8}$ However, our findings on the elevated ratio of smokers in TTPs suggest that the role of smoking should not be excluded in the last steps of the multistage process of cancer formation.

We may conclude that hereditary factors play a remarkable role not only in the formation of a certain portion of testicular cancers, but also in the elevated cancer risk and decreased male-female ratio of the offspring of TTPs. Brothers and offspring may be regarded as having a high probability of genome instability with harboring susceptibility genes, but different genes may be involved in determining the risk of fraternal and childhood cancers. Since the relative risk of testicular cancer is greater in brothers than in fathers of TTPs, this finding is consistent either with the recessive model of inheritance, ${ }^{3}$ or with $\mathrm{X}$-linked susceptibility genes. ${ }^{7,37}$ The role of a single or various dominant genes with perhaps age-specific penetrance, or other genes of the offspring, overlapping with the father's susceptibility must be refined in molecular studies. Therefore, we recommend an aggressive followup in all close relatives of TTPs, and emphasize that particular attention should be paid to tumors occurring in the childhood of the offspring.

\section{References}

1. Hoff Wanderas E, Tretli S, Fossa SD: Trends in incidence of testicular cancer in Norway 1955-1992. Eur J Cancer 31A: 2044-2048, 1995

2. Bergström R, Adami HO, Möhner M, et al: Increase in testicular cancer incidence in six European countries: a birth cohort phenomenon. J Natl Cancer Inst 88: 727-733, 1996

3. Heimdal $K$, Olsson $H$, Tretli S, et al: Familial testicular cancer in Norway and southern Sweden. Br J Cancer 73: 964-969, 1996

4. Sonnenveld DJA, Sleijfer DTh, Schrafford Koops H, et al: Familial testicular cancer in a single-centre population. Eur J Cancer 35:1368-1373, 1999

5. Dong C, Lönnstedt I, Hemminki K: Familial testicular cancer and second primary cancers in testicular cancer patients by histological type. Eur J Cancer 37: 1878-1885, 2001 
6. Spermon JR, Witjes JA, Nap M, Kiemeney LALM: Cancer incidence in relatives of patients with testicular cancer in the Eastern part of Netherlands. Urology 57: 747-752, 2001

7. Rapley EA, Crockford GP, Easton DF, et al: Localisation of susceptibility genes for familial testicular cancer. APMIS 111: 128-135, 2001

8. Buetow SA: Epidemiology of testicular cancer. Epidem Rev 17: 433-449, 1995

9. Bokemeyer C, Schmoll H-J, Schöffsky P, et al: Bilateral testicular tumors: Prevalence and clinical implications. Eur J Cancer 29A: 874-876, 1993

10. Geczi L, Gomez F, Baki M, Bodrogi I: The incidence, prognosis, clinical and histological characteristics, treatment, and outcome of patients with bilateral germ cell testicular cancer in Hungary. J Cancer Res Clin Oncol 129:309-315, 2003

11. Nicholson PW, Harland SJ: Inheritance and testicular cancer. Br J Cancer 71:421-426, 1995

12. Khoury MJ, Beaty TH, Liang KY: Can familial aggregation of disease be explained by familial aggregation of environmental risk factors? Am J Epidemiol 127: 674-683, 1988

13. Swerdlow AJ, De Stavola BL, Swanwick MA, et al: Risk factors for testicular cancer: a case-control study in twins. Br J Cancer 80: 1098-1102, 1999.

14. Huyghe E, Matsuda T, Thonneau, P: Increasing incidence of testicular cancer worldwide: a review. J Urol 170: 5-11, 2003

15. Swerdlow AJ, Douglas AJ, Huttly SRA, Smith PG: Cancer of the testis, socioeconomic status, and occupation. Br J Ind Med 48: 670-674, 1991

16. "GraphPad Software, InStat guide to choosing and interpreting statistical tests, 1998, GraphPad Software, Inc., San Diego California USA, www.graphpad.com

17. Gundy S, Babosa M, Baki M. Offspring of testicular cancer patients: A model for male-mediated mutagenesis and carcinogenesis, In: Reproductive Toxicology. (Ed: Richardson M), Weinheim, New York, Basel, Cambridge, Tokyo, VCH, 1993, pp. 143-151

18. Babosa M, Baki M, Bodrogi I, Gundy S: A study of children fathered by men treated for testicular cancer, conceived before, during and after chemotherapy. Med Ped Oncol 22: 33-38, 1994

19. Senturia YD, Peckham CS, Peckham MJ: Children fathered by men treated for testicular cancer. Lancet 2: 766-769, 1985

20. Fried P, Steinfeld $R$, Casileth B, Steinfeld A: Incidence of developmental handicaps among the offspring of men treated for testicular seminoma. Int J Androl 10: 385-387, 1987
21. Heimdal $K$, Olsson H, Tretli $S$, et al: Risk of cancer in relatives of testicular cancer patients. Br J Cancer 73: 970-973, 1996

22. Hemminki K, Vaittinen $P$ : Effect of paternal and maternal cancer on cancer in the offspring: a population-based study. Cancer Epidem Biom Prev 6: 993-997, 1997

23. Olsen JH, Boice JD, Seersholm N, et al: Cancer in the parents of children with cancer. New Eng J Med 333:1594-1599, 1995

24. Moller $H$ : Clues to the aetiology of testicular germ cell tumors from descriptive epidemiology. Eur Urol 233: 8-13, 1993

25. Chaganti RSK, Houldsworth J: Genetics and biology of adult human male germ cell tumors. Cancer Res 60: 1475-1482, 2000

26. Kreidberg JA, Sariola H, Loring JM, et al: WT-1 is required for early kidney development. Cell 74: 679-691, 1993

27. Chompret A: The Li-Fraumeni syndrome. Biochimie 84: 7582,2000

28. Knudson AGJ, Strong LC: Mutation and cancer: neuroblastoma and pheochromocytoma. Am J Hum Genet 24: 514-522, 1972

29. Kim E, Nichols KE, Malkin D, et al: Germ-line p53 mutations predispose to a wide spectrum of early-onset cancers. Cancer Epidem Biom Prev 10: 83-87, 2001

30. Heimdal K, Lothe RA, Lystad S, et al: No germ line TP53 mutations detected in familial and bilateral testicular cancer. Genes Chromosomes Cancer 6: 92-97, 1993

31. Jones RH, Vasey $P$ : New directions in testicular cancer; molecular determinants of oncogenesis and treatment success. Eur J Cancer 39: 147-156, 2003

32. Peltomaki $P$, Lothe $R$, Borresen AL, et al: Altered dosage of the sex chromosomes in human testicular cancer: a molecular genetic study. Int J Cancer 47: 518-522, 1991

33. Moller H: Trends in sex-ratio, testicular cancer and male reproductive hazards: Are they connected? APMIS 106: 232239, 1998

34. Moller H, Skakkebaek NE: Risk of testicular cancer in subfertile men. Br Med J 318: 559-562, 1999

35. Fossa SD, Kravdal O: Fertility in Norwegian testicular cancer patients. Br J Cancer 82: 737-741, 2000

36. Demographic Yearbook. Hungarian Central Statistical Office, 2003, Budapest

37. Hemminki K, Vaittinen $P$, Dong $C$, Easton D: Sibling risks in cancer: clues to recessive or X-linked genes? Br J Cancer 84: 388-391, 2001 